\title{
Molecular cloning and characterization of the promoter region of the calcineurin $A \alpha$ gene
}

\author{
Chang-Duk CHANG,* Takehiko TAKEDA, ${ }^{*}$ Hideyuki MUKAI,* Hisato SHUNTOH,* Takayoshi KUNO*† \\ and Chikako TANAKA* \\ *Department of Pharmacology, School of Medicine, Kobe University, Chuo-ku, Kobe 650, Japan
}

\begin{abstract}
The 5'-flanking region of the calcineurin $\mathrm{A} \alpha$ gene was isolated from a rat genomic library. It lacked TATA and CAAT boxes but contained $\mathrm{G}+\mathrm{C}$-rich regions, and was demonstrated to function as a strong promoter in neuronal cell lines (NG108-15 mouse neuroblastoma $\times$ rat glioma hybrid cells or N1E115 mouse neuroblastoma cells), but not in nonneuronal cell lines (C6 rat glioma or L-M mouse fibroblastoid cells) in a transient chloramphenicol acetyltransferase expression assay. Deletion analysis of the $5^{\prime}$-flanking region revealed that the core promoter region, as well as the sequence critical for cell-type-specific-promoter function, reside within the fragment -107 to +157 with respect to the major transcription initiation site.
\end{abstract}

\section{INTRODUCTION}

Calmodulin-dependent protein phosphatase, calcineurin, corresponds to protein phosphatase type $2 \mathrm{~B}$, one of four principal types of serine/threonine-specific protein phosphatases present in mammalian tissues (Cohen, 1989). It was originally discovered as a calmodulin-binding protein in mammalian brain (Wang \& Desai, 1977). Recently, it has been suggested to be a common target for cyclophilin-cyclosporin A and FKBP-FK506 complexes (Liu et al., 1991). The phosphatase is a heterodimer of the catalytic (calcineurin A) and regulatory (calcineurin B) subunits (Wang \& Desai, 1977; Klee et al., 1979). Complementary DNAs encoding two distinct isoforms of calcineurin A (A $\alpha$ and $\mathrm{A} \beta$ ) have been isolated (Ito et al., 1989; Kuno et al., 1989; Guerini \& Klee, 1989; Kincaid et al., 1990).

Calcineurin $A \alpha$ is a major isoform of calcineurin $A$ in the rat brain, and is highly expressed in the neuronal cells (Ito et al., 1989; Takaishi et al., 1991; Kuno et al., 1992). In order to understand the mechanisms responsible for the neuronpreferential expression of calcineurin $A \alpha$, information about its genomic structure, especially its promoter region, is required.

Using cloned rat calcineurin A $\alpha$ cDNA (Ito et al., 1989), we have isolated the 5 -terminal region of the rat calcineurin $A \alpha$ gene, demonstrated neuronal-cell-type-specific potent promoter activity in the $5^{\prime}$-flanking region, and characterized the region by deletion analysis using a transient chloramphenicol acetyltransferase (CAT) expression assay.

\section{MATERIALS AND METHODS}

\section{Materials}

Restriction endonucleases, the Klenow fragment of DNA polymerase, T4 DNA ligase, a DNA deletion kit, and a random primer DNA labelling kit were purchased from Takara Shuzo Co., Kyoto, Japan; and $\left[{ }^{14} \mathrm{C}\right]$ chloramphenicol was obtained from Amersham. All other reagents were of analytical grade.

\section{General methods}

Preparation of plasmid DNA, restriction enzyme digestion, agarose gel electrophoresis of DNA, labelling of DNA, DNA ligation, and bacterial transformation were carried out using standard methods (Sambrook et al., 1989, and references therein).

\section{Screening of the library and sequence analysis}

A rat genomic library in Charon 4A (Clontech, Palo Alto, CA, U.S.A.) was screened using the $5^{\prime}$-cDNA probe $\left[245 \mathrm{bp} 5^{\prime}\right.$-end fragment of calcineurin $\mathrm{A} \alpha \mathrm{cDNA}$ (Ito et al., 1989)]. A positive clone was purified and restriction fragments were subjected to Southern-blot analysis using the 5'-cDNA probe. An approx. $5 \mathrm{kbp}$ EcoRI-EcoRI fragment, which hybridized with the probe was subcloned into pUC18. Nucleotide-sequence analysis was performed using the enzymic chain termination method in conjugation with M13-derived vectors (Sanger et al., 1977). The sequence was determined from both strands by using synthetic oligonucleotide primers selected at convenient intervals.

\section{Primer extension and S1 mapping}

Total and poly $\left(\mathrm{A}^{+}\right)$RNA were isolated from rat brain by the guanidine isothiocyanate method (Chirgwin et al., 1979). A synthetic oligonucleotide corresponding to nucleotides -169 to -140 with respect to the translation-initiation site in antisense orientation was used in primer-extension experiments. After 5'labelling with ${ }^{32} \mathrm{P}$, the oligonucleotide was hybridized to $1 \mu \mathrm{g}$ of poly $\left(\mathrm{A}^{+}\right)$RNA. The primer was extended using reverse transcriptase for $45 \mathrm{~min}$ at $42^{\circ} \mathrm{C}$, and the reaction products were ethanol-precipitated and dissolved in $0.1 \mathrm{M}-\mathrm{NaOH}$ containing 1 mM-EDTA.

Single-stranded 5'-labelled probe for $\mathrm{S} 1$ analysis was prepared as follows. A $1 \mathrm{~kb}$ Pst I-SalI genomic fragment (see Fig. 1) was cloned into bacteriophage M13mp19, and single-stranded DNA corresponding to the sense strand was hybridized to the 30-base oligonucleotide primer described above which was $5^{\prime}{ }^{32} \mathrm{P}$ labelled. The primer was extended using the Klenow fragment of DNA polymerase. Single-stranded 5'-end-labelled probe was then generated by digesting the synthesized double-stranded DNA with HindIII and separating the strand by alkaline gel electrophoresis. This probe was hybridized to the total RNA from rat brain at $52{ }^{\circ} \mathrm{C}$ for $16 \mathrm{~h}$ in $80 \%$ (v/v) formamide $/ 0.4 \mathrm{M}$ $\mathrm{NaCl}$. At the end of the hybridization, nucleic acids were then digested with 100 units of S1 nuclease for $2 \mathrm{~h}$ at $37^{\circ} \mathrm{C}$. The

\footnotetext{
Abbreviation used: CAT, chloramphenicol acetyltransferase.

$\uparrow$ To whom correspondence should be addressed.

The nucleotide sequence data reported in this paper will appear in the DDBJ, EMBL and GenBank Nucleotide Sequence Databases under the accession number D10408.
} 
reaction products were extracted with phenol/chloroform and precipitated with ethanol. The reaction products from the primer extension and S1 nuclease digestion were subjected to electrophoresis on DNA-sequencing gels. The sizes of the reaction products were determined by parallel electrophoresis of a DNA sequencing reaction primed with the same 30-base antisense oligonucleotide described above.

\section{Plasmids and construction of a CAT expression vector}

A number of $5^{\prime}$ to $3^{\prime}$ and $3^{\prime}$ to $5^{\prime}$ deletion clones of the $5^{\prime}$ flanking region of calcineurin $A \alpha$ gene were prepared using the DNA deletion kit according to manufacturer's specifications. Dideoxynucleotide sequencing was used to determine the precise end of the deletion clones. Deleted fragments were subcloned into a HindIII site located upstream of the $C A T$ gene in pSVOOCAT, a low-background promoterless CAT expression vector (Araki et al., 1988), in the same orientation relative to the $C A T$ gene. In some experiments, the deleted fragment was ligated into a BamHI site located 3 ' downstream of the $C A T$ gene in the same or reverse orientation relative to the $C A T$ gene. In parallel with these constructs, pSV2CAT (Gorman et al., 1982), containing the SV40 early promoter region, was used as a positive control.

\section{Cell culture, DNA transfections and CAT assays}

C6 rat glioma cells and L-M mouse cells were obtained from Dainippon Pharmaceutical Company, Ltd., Japan, and NG10815 mouse neuroblastoma $\times$ rat glioma hybrid cells and N1E115 mouse neuroblastoma cells were obtained from Dr. T. Amano (Mitsubishi-Kasei Institute of Life Science, Machida, Japan). These cell lines were cultured in Dulbecco's modified Eagle's medium. NG108-15 cells were supplemented with $5 \%$ (v/v) fetal calf serum (GIBCO), $100 \mu \mathrm{M}$-hypoxanthine, $1 \mu \mathrm{M}$-aminopterin, and $20 \mu \mathrm{M}$-thymidine. Other cell lines were supplemented with $10 \%(\mathrm{v} / \mathrm{v})$ fetal calf serum only. Plasmid DNA was transfected into these cell lines by the calcium phosphate co-precipitation method (Graham \& van der Eb, 1973). pSV- $\beta$-Galactosidase Control Plasmid (Promega) was included in each transfection and $\beta$-galactosidase activity was used to normalize the variations caused by the differences in transfection efficiency. CAT and $\beta$ galactosidase activities were determined as described (Gorman $\boldsymbol{e t}$ al., 1982; Nielsen et al., 1983).

\section{RESULTS}

Primary sequence of the $5^{\prime}$-flanking region of the rat calcineurin A $\alpha$ gene

A rat genomic library was screened with a $5^{\prime}$ fragment of rat calcineurin $\mathrm{A} \alpha$ cDNA. An approx. $5 \mathrm{kbp}$ EcoRI-EcoRI fragment, which contains the sequence to the 5 '-end of the ATG translation-initiation site of the calcineurin $A \alpha$ gene, was isolated (Fig. 1). A $1833 \mathrm{bp} \mathrm{PstI-HindIII} \mathrm{fragment} \mathrm{was} \mathrm{subcloned} \mathrm{and}$ sequenced. This fragment contained $895 \mathrm{bp}$ of the 5 -flanking DNA and 5 '-non-coding region, 58 bp of the translated region on exon 1, and part of the first intron (Fig. 2). Exon 1 contains the nucleotides coding for amino-acid residues 1-20, including the initiation Met residue. The 5 -flanking region lacks TATA and CAAT boxes but contains $\mathrm{G}+\mathrm{C}$-rich regions. The region between nucleotides +359 and -536 , with respect to the major transcription initiation site, contains four putative SP1 (Mitchell \& Tjian, 1989) binding sites.

\section{Primer-extension and S1-mapping analyses}

The absence of a TATA box in the putative promoter region

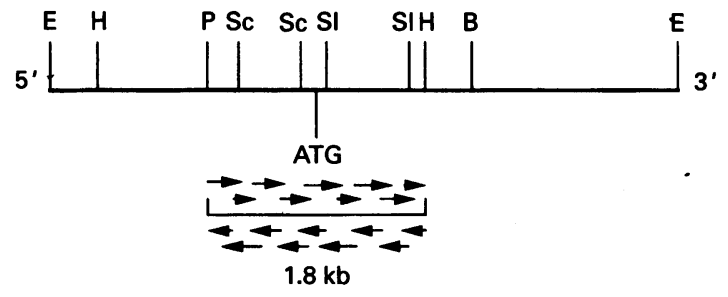

Fig. 1. Restriction map of the $5^{\prime}$-flanking region of the rat calcineurin $A \alpha$ gene

Abbreviations used: ATG, start codon; E, EcoRI; H, HindIII; P, PstI; Sc, SacI; S1, SalI; B, BamHI. Arrows represent the sequence overlaps in the sequencing strategy.

suggests the possibility that there may be multiple sites of transcription initiation. To test this possibility and to provide support for the belief that the isolated 5 -flanking segment contained the promoter, primer-extension and S1-mapping analyses were carried out (Fig. 3). The results of these two analyses were consistent with one another and indicated that calcineurin $A \alpha$ mRNA transcription in the rat brain is initiated at multiple sites. At least three sites of initiation were found around nucleotides $-359,-313$, and -266 with respect to the translation initiation site. These results suggest that no intron is located at the $5^{\prime}$-end of the ATG initiation codon, and that the promoter region is in fact located within the isolated segment. The nucleotides were numbered from the major start site of transcription $(-359$ with respect to the translation initiation

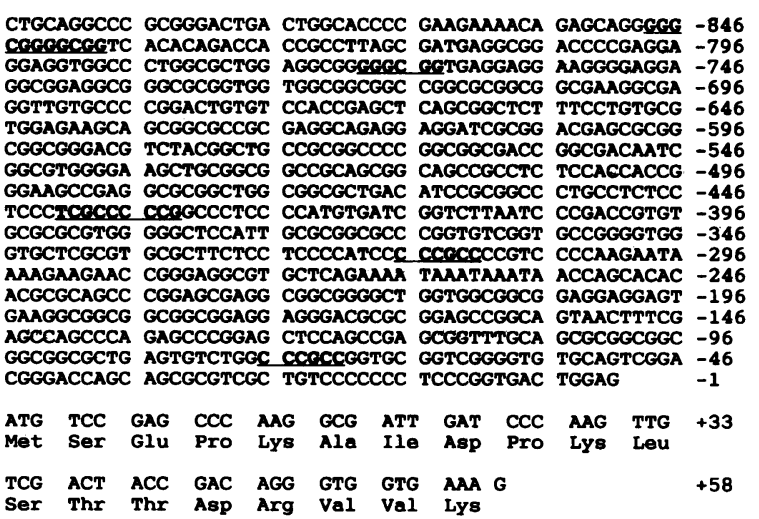

GTAAGCGCAG CGCCGCGGCG GCCCGGGGTG CACCGAGTGC CGCAGCGACC +108 GTCCGCCCCT CCCCCGCCCC GGTTGTCCCT CTCCAGCTAG CGCCGGGGAC +158 CTTCTAGGAT CTCCTGCAAG AGGCGATCCC CTCCTCCGCC GCGCCCTGCC + 208 CCCACACCGC CCACCCGGC CTAATGGGG CTTTTATTTA TGTATGTATT + 258 TATTTTTATT TATTTATTTT TGTGGACCGG GGGGCAGCAG TTGGCAAATG +308 CCTGAGTGGC TGGGAGGCGG TGGCGGGGGT GGCGGTGGCG GGAGGGGGCG +358 GGAAGTGGGT GGCTGCTCGC AGGCTTGCAT GGGATCGGGT TTATGGTTTG +458 GGAAGTGGT GGCTGCTCGC AGGCTTGCAT GGGATCGGT TTATGGTTTG +458 GGCATTTTTA TGTGGCCGTG GCTTGCCGCG GACTGGCTCG CCCCGGCACA +558 TTGCTCCAGG CGCTCCATTG CAGCAGTTCC CTGGGCGCCC CCTCCCCCTC +608 CGCGGGAGG GCCTGCACAG GACTCGCGAG AGAGCGGGAG AGCGTGGGG +658 GAGCCCAGCT CCGGCTGCCG CGCGCCGCGG GGGGGGGGA CCGGGGCCGC + 708 GTGGGGGCAG CGCCAGGCG GGGACGACCG GAGCCCCCG CGCCGCCCCG +758 GGATTPCCCC GCAGGCCCGG AGCGACGCGA GCGGTGGTGA TCCTCTGTCG + +808 ACCTCCCTTG CCACCCATGG CTGACTGCCG CCGACCTGTC ATTGCTCTTA + 858 GAGCTCACCT TGCTCCCTTC CCCCAAGCTT GTGTGTGTGT GTGTTGGGG +908

Fig. 2. Nucleotide sequence of the $5^{\prime}$-flanking region of the rat calcineurin Aa gene

The 1833 bp PstI-HindIII fragment of Fig. 1 was sequenced. Note the absence of TATA and CAAT sequences. The region is $\mathrm{G}+\mathrm{C}$ rich and contains SP1 binding sites (GGGCGG or CCCGCC), including two which are overlapping as underlined. The putative consensus sequence for neuronally expressed genes (TCGCCCCCG) is also underlined. Nucleotide numbering is relative to the major transcription initiation site. 


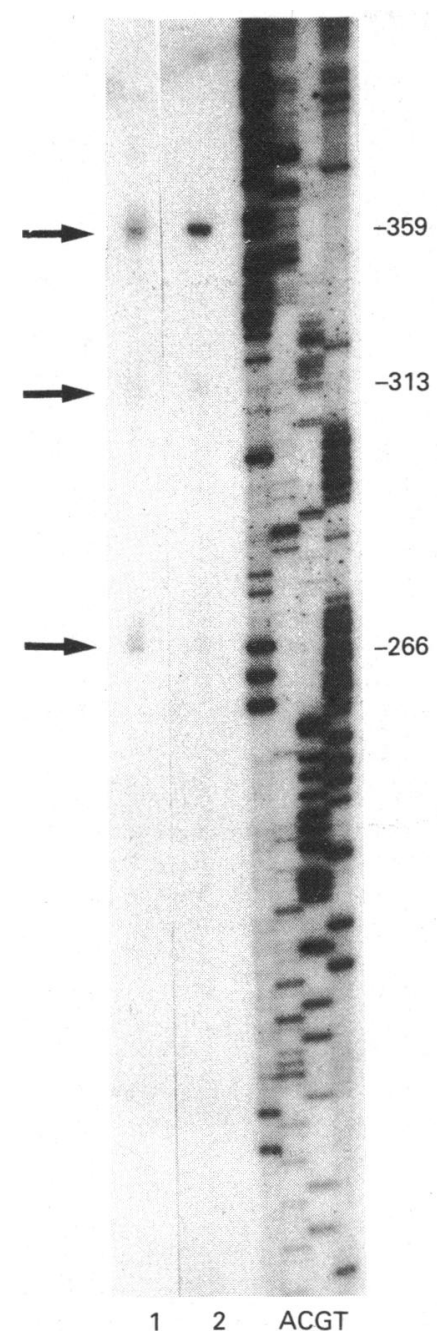

Fig. 3. Primer-extension and S1-mapping analyses

Analyses were carried out as described in the Materials and methods section. Lane 1 is primer extension and lane 2 is $\mathrm{S} 1$ mapping. The sequencing reaction shown on the right of the figure used the same 30 -nucleotide oligomer as primer as was used in primer-extension and S1-mapping analyses, and the ladder is in the order adenine (A), eytosine $(C)$, guanine $(G)$, thymidine $(T)$. The nucleotide positions are numbered with respect to the major transcription initiation site. Arrows indicate three common bands, suggesting multiple transcription initiation sites.

site). Consequently, the three start sites of transcription are renumbered as $+1,+47$, and +94 respectively (Fig. 3 ).

\section{Demonstration of the neuronal-cell-type-specific potent promoter activity of the 5 -flanking region}

We constructed fusion genes containing calcineurin $\mathrm{A} \alpha 5^{\prime}$ flanking sequences and the bacterial $C A T$ structural gene and transfected the constructs into several cell lines. Two neuronal cell lines, NG108-15 mouse neuroblastoma $\times$ rat glioma hybrid cells and N1E115 mouse neuroblastoma cells, were shown to be very active in endogenous expression of the calcineurin $\mathrm{A} \alpha$ gene; on the other hand, non-neuronal cell lines such as $\mathrm{C} 6$ rat glioma cells and L-M mouse fibroblastoid cells were shown to be inactive (results not shown). Parallel transfection experiments were first performed with pK100CAT (containing the sequence from -536 to +324$)$, together with a promoterless construct pSVOOCAT (Araki et al., 1988) as a negative control, and with pSV2CAT (Gorman et al., 1982) as a positive control. When

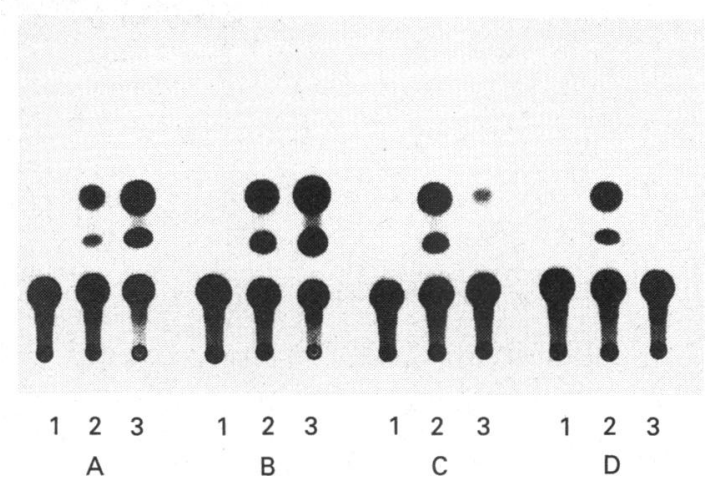

Fig. 4. Neuronal-cell-type-specific promoter activity of the rat calcineurin $A \alpha$ gene/CAT gene constructs in a transient expression assay

Autoradiograms of $C A T$ assays from NG108-15 mouse neuroblastoma $\times$ rat glioma hybrid (A), N1E115 mouse neuroblastoma (B), C6 rat glioma (C), and L-M mouse fibroblastoid (D) cell lysates after transfection with promoterless (pSVOOCAT, lanes 1), constitutive SV40-promoter/enhancer-containing (pSV2CAT, lanes 2), and calcineurin-A $\alpha$-promoter-containing (pK100CAT, nucleotides -536 to +324 , lanes 3 ) expression plasmids.

CAT activity was determined $48 \mathrm{~h}$ or $72 \mathrm{~h}$ after transfection, the extracts from those cell lines transfected with pSVOOCAT had negligible activity, and those transfected with pSV2CAT had high activity (Fig. 4 and Table 1). The CAT activity in NG10815 cells and N1E115 cells transfected with pK100CAT ( -536 to $+324)$ was $250 \%$ and $170 \%$ of that noted with pSV2CAT respectively. On the other hand, the CAT activity in C6 cells and L-M cells transfected with pK100CAT was only $21 \%$ and $14 \%$ of that noted with pSV2CAT respectively. These results indicate that an $860 \mathrm{bp}$ fragment $(-536$ to +324$)$ functioned as a neuronal-cell-type-specific potent promoter.

\section{Deletion analysis of the $5^{\prime}$-flanking region}

To delineate potentially functional regulatory domains within the 860 bp fragment $(-536$ to +324$)$, various deletion clones were generated. Parallel transfection experiments were performed with these deletion constructs in NG108-15 cells. As shown in Table 2 and Fig. 5, deletion of a segment from -536 to -211 or a segment from +156 to +324 had no effect on the CAT activity in these cells. Deletion of the segment from -210 to -188 reduced the promoter activity to $21 \%$ of that noted with an undeleted construct (Fig. 5 and Table 2). These results suggest that the 23 nucleotides between -210 and -187 contain an upregulatory cis-element. This up-regulatory effect seems to be position-dependent as the basic promoter activity of pK287CAT $(-126$ to +232$)$ was not potentiated when the sequences containing these nucleotides were ligated in both orientations at the BamHI site located 3'-downstream of the CAT gene (Table 3 ). Continual deletion of the segment from nucleotides -187 to -108 had no significant effect on the promoter activity in NG108-15 cells (Fig. 5 and Table 2). However, further deletion of sequences between -107 and -87 abolished CAT activity in these cells. These results suggest that pK146CAT $(-107$ to +232 ) is the smallest $5^{\prime}$ deletion construct examined which contains core promoter elements (Fig. 5 and Table 2). The most notable finding with $3^{\prime}$ deletion constructs was a marked reduction in promoter activity from pK199CAT $(-306$ to +157$)$ to pK293CAT $(-306$ to +102$)$ (Fig. 5 and Table 2). Thus, the core promoter element appears to reside within the sequence -107 to +157

Parallel transfection experiments were performed with several deletion constructs into the four cell lines to define the sequences responsible for neuronal-cell-type-specific promoter activity in 
Table 1. Neuronal-cell-type-specific promoter function of 5'-flanking sequences of rat calcineurin $A \alpha$ gene in a transient expression assay

Results are expressed as the amount $(\%)$ of chloramphenicol acetylated by $25 \mu$ l of extract. Results were normalized for the $\beta$-galactosidase control. Values are means \pm S.E.M. of three independent transfection experiments.

\begin{tabular}{|c|c|c|c|c|c|}
\hline \multirow{2}{*}{$\begin{array}{l}\text { CAT construct } \\
\text { (promoter fragment) }\end{array}$} & \multirow[b]{2}{*}{ Cell lines... } & \multicolumn{4}{|c|}{ Promoter activity ( $\%)$} \\
\hline & & NG108-15 & N1E115 & $\mathrm{C} 6$ & L-M \\
\hline pK100CAT $(-536$ to +324$)$ & & $15.6 \pm 3.2$ & $20.4 \pm 3.8$ & $2.5 \pm 0.7$ & $1.4 \pm 0.3$ \\
\hline pK219CAT $(-210$ to +232$)$ & & $16.0 \pm 2.2$ & $19.7 \pm 2.6$ & $2.3 \pm 0.5$ & $1.0 \pm 0.3$ \\
\hline pK199CAT $(-306$ to +157$)$ & & $17.1 \pm 2.6$ & $18.5 \pm 3.1$ & $2.7 \pm 0.8$ & $1.2 \pm 0.4$ \\
\hline pK146CAT $(-107$ to +232$)$ & & $3.1 \pm 0.5$ & $4.0 \pm 0.8$ & $1.3 \pm 0.5$ & $1.2 \pm 0.3$ \\
\hline pK147CAT $(-87$ to +232$)$ & & $1.4 \pm 0.3$ & $1.3 \pm 0.3$ & $1.0 \pm 0.4$ & $1.3 \pm 0.5$ \\
\hline pK293CAT $(-306$ to +102$)$ & & $1.2 \pm 0.2$ & $0.9 \pm 0.4$ & $1.4 \pm 0.2$ & $1.2 \pm 0.1$ \\
\hline pSVOOCAT & & $1.2 \pm 0.3$ & $1.2 \pm 0.2$ & $0.9 \pm 0.4$ & $1.3 \pm 0.3$ \\
\hline pSV2CAT & & $6.2 \pm 2.5$ & $12.3 \pm 2.0$ & $11.6 \pm 3.1$ & $10.0 \pm 2.5$ \\
\hline
\end{tabular}

Table 2. Deletion analysis of rat calcineurin $A \alpha$ promoter activity in region from -536 to +324 in NG108-15 cells

Results are expressed as the amount (\%) of chloramphenicol acetylated by $25 \mu \mathrm{l}$ of extract. Values are means \pm S.E.M. of three independent transfection experiments.

\begin{tabular}{lc}
\hline $\begin{array}{l}\text { CAT construct } \\
\text { (promoter fragment) }\end{array}$ & $\begin{array}{c}\text { Activity } \\
\text { (\% of pK100CAT) }\end{array}$ \\
\hline pK100CAT $(-536$ to +324$)$ & $15.6 \pm 3.2(100)$ \\
pK133CAT $(-306$ to +232$)$ & $17.1 \pm 2.5(110)$ \\
pK225CAT $(-264$ to +232$)$ & $15.0 \pm 1.8(96)$ \\
pK219CAT $(-210$ to +232$)$ & $16.0 \pm 2.2(103)$ \\
pK288CAT $(-187$ to +232$)$ & $3.3 \pm 0.5(21)$ \\
pK289CAT $(-165$ to +232$)$ & $3.7 \pm 0.4(24)$ \\
pK287CAT $(-126$ to +232$)$ & $3.5 \pm 0.7(22)$ \\
pK146CAT $(-107$ to +232$)$ & $3.1 \pm 0.5(20)$ \\
pK147CAT $(-87$ to +232$)$ & $1.4 \pm 0.3(10)$ \\
pK148CAT $(-28$ to +232$)$ & $1.3 \pm 0.4(9)$ \\
pK199CAT $(-306$ to +157$)$ & $17.1 \pm 2.6(110)$ \\
pK293CAT $(-306$ to +102$)$ & $1.2 \pm 0.2(8)$ \\
pK292CAT $(-306$ to +57$)$ & $1.0 \pm 0.4(6)$ \\
pK152CAT $(-306$ to -121$)$ & $1.2 \pm 0.4(8)$ \\
pSVOOCAT & $1.2 \pm 0.3(8)$
\end{tabular}

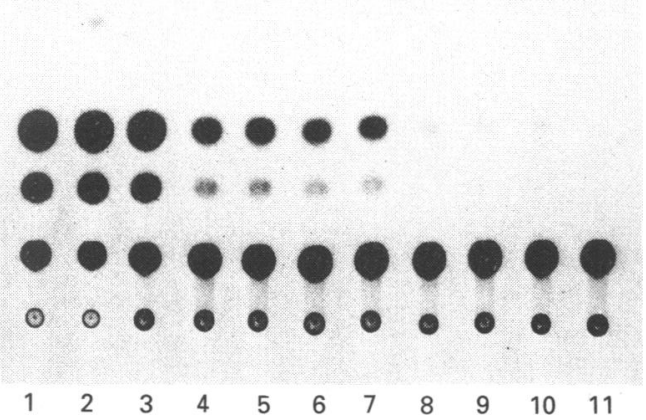

Fig. 5. Deletion analysis of calcineurin $A \alpha$ promoter function in the NG10815 cell line

Autoradiogram of CAT assays from NG108-15 mouse neuroblastoma $\times$ rat glioma hybrid cell lysates after transfection with calcineurin promoter/CAT gene constructs, pK100CAT (nucleotides -536 to +324 , lane 1$)$, pK133CAT $(-306$ to +232 lane 2), pK219CAT $(-210$ to +232 , lane 3$)$, pK288CAT $(-187$ to +232 , lane 4$)$, pK289CAT $(-165$ to +232 , lane 5$)$, pK287CAT $(-126$ to +232 , lane 6$)$, pK146CAT $(-107$ to +232 , lane 7$)$ pK 147CAT $(-87$ to +232 , lane 8$)$, pK148CAT $(-28$ to +232 , lane 9), pK293CAT (-306 to +102, lane 10), and pSVOOCAT (promoterless plasmid, lane 11)
Table 3. Effects of fragment insertion on the CAT activity of pK287CAT in NG108-15 cells

Nucleotide fragments containing a potential up-regulatory element was ligated in both orientations at the BamHI site located $3^{\prime}$ downstream of the $C A T$ gene. Results are expressed as the amount (\%) of chloramphenicol acetylated by $25 \mu \mathrm{l}$ of extract. Values are means \pm S.E.M. of three independent transfection experiments.

\begin{tabular}{lccc}
\hline $\begin{array}{l}\text { CAT } \\
\text { construct }\end{array}$ & $\begin{array}{c}\text { Promoter } \\
\text { fragment }\end{array}$ & $\begin{array}{c}\text { Inserted } \\
\text { fragment }\end{array}$ & $\begin{array}{c}\text { Activity } \\
\text { (\% of } \\
\text { pK287CAT) }\end{array}$ \\
\hline pK287CAT & -126 to +232 & & $3.5 \pm 0.7(100)$ \\
pK152CAT & -306 to -121 & & $1.2 \pm 0.4(34)$ \\
pK133CAT & -306 to +232 & & $17.1 \pm 2.5(489)$ \\
pK302CAT & -126 to +232 & -306 to -121 & $3.3 \pm 0.5(94)$ \\
pK303CAT & -126 to +232 & -306 to -121 & $3.7 \pm 0.5(110)$ \\
& & (reverse) & \\
pK308CAT & -126 to +232 & -306 to +232 & $3.0 \pm 0.4(86)$ \\
pK307CAT & -126 to +232 & -306 to +232 & $3.6 \pm 0.8(100)$ \\
& & (reverse) & \\
\hline
\end{tabular}

more detail. The CAT activity observed with pK219CAT $(-210$ to +232$)$ and pK199CAT $(-306$ to +157$)$ was similar to that seen with undeleted construct pK100CAT $(-536$ to +325$)$ in the four cell lines examined (Table 1). Transfection of pK146CAT $(-107$ to +232$)$ in these cell lines revealed that significant CAT activity was observed only in the two neuronal cell lines (Table 1). $\mathrm{pK} 147 \mathrm{CAT}(-87$ to +232$)$ and $\mathrm{pK} 293 \mathrm{CAT}(-306$ to +102$)$ showed only negligible activity in all the cell lines examined (Table 1). These results suggest that the sequence between nucleotides -107 and +157 also seems to be critical for neuronal-cell-type-specific promoter function.

\section{DISCUSSION}

In this study, we have cloned the promoter region of the rat calcineurin $\mathrm{A} \alpha$ gene and demonstrated that the region has potent neuronal-cell-type-specific promoter activity by transient transfection experiments. Thus, the calcineurin $\mathrm{A} \alpha$ promoter can be used to direct expression of any protein foreign to neuronal cell lines.

The analysis of a number of both $5^{\prime}$ to $3^{\prime}$ and $3^{\prime}$ to $5^{\prime}$ deletion clones of the 5'-flanking DNA allowed us to conclude that the core promoter region resides within the segment -107 to +157 . From the results in Table 1 there seems to be a strong cell-typespecific element between -210 and -107 . A position-dependent up-regulatory element was found to be located between nucleo- 
tides -210 and -187 ; however, this element does not seem to be essential to cell-type-specific expression. We could not find any other cis-acting regulatory elements in the calcineurin $\mathrm{A} \alpha \mathrm{5}^{\prime}$ flanking region. The 20 nucleotides between -107 and -87 and the 55 nucleotides between +102 and +157 seem to contain important elements for the expression of core promoter activity because elimination of these sequences abolished basic promoter activity. The sequence between nucleotides -107 and +157 also seems to be critical for cell-type-specific promoter function.

S1-nuclease-mapping and primer-extension experiments suggested the presence of multiple start sites for transcription (Fig. 3 ). The structure found in the calcineurin $\mathrm{A} \alpha 5^{\prime}$-flanking region, with highly heterogeneous start sites of transcription, absence of TATA and CAAT boxes, and the abundance of $\mathrm{G}$ and $\mathrm{C}$ residues, has been typically found in constitutively expressed housekeeping genes (Bird, 1986), although an increasing number of brainspecific genes with such features are being found (Vibert et al., 1989).

Another neuronally expressed gene, the synapsin I gene, also has a promoter sequence that is $\mathrm{G}+\mathrm{C}$-rich, and TATA- and CAAT-less, as was reported by Sauerwald et al. (1990). They also demonstrated that a short, housekeeping-type upstream sequence of $2255^{\prime}$-flanking and $1055^{\prime}$-untranslated nucleotides of the synapsin I gene is sufficient to promote neural-cell-typespecific transient CAT expression in neuroblastoma cells, but not in fibroblastoid cells. A $74 \mathrm{bp}$ fragment of the 5 -flanking sequence of synapsin I seems to be critical for neuronal-cell-typespecific promoter function. It contains the cyclic AMP-responsive element and putative SNN (synapsin I, neurofilament and NGF receptor) consensus sequence (Sauerwald et al., 1990). Interestingly, the core sequence for the SNN consensus, TCGCCCCCG, is also found in the 5 -flanking region of the calcineurin $A \alpha$ gene ( -82 to -74 , Fig. 2).

Further deletion or point mutation analyses to define specific sequences of the promoter responsible for the cell-specific expression is difficult, because the core promoter activity is not high enough to distinguish it from cell-type-specific enhancing activity. Cloning of the $5^{\prime}$-flanking region of calcineurin $B$ gene, which coexpresses with calcineurin $\mathrm{A} \alpha$, has still to be done. Comparison of the two 5'-flanking regions may contribute to elucidation of the mechanism for neuron-preferential expression of calcineurin.
We thank Dr. Yoshitaka Ono for critical comments and Ms. Mieko Matsui and Mr. Hideki Okazawa for assistance in the experimental work. These studies were supported by research grants from the Ministry of Education, Science and Culture, and the Ministry of Health and Welfare, Japan.

\section{REFERENCES}

Araki, E., Shimada, F., Shichiri, M., Mori, M. \& Ebina, Y. (1988) Nucleic Acids Res. 16, 1627

Bird, A. P. (1986) Nature (London) 321, 209-213

Chirgwin, J. M., Przybyla, B. E., McDonald, R. J. \& Rutter, W. J. (1979) Biochemistry 18, 5294-5299

Cohen, P. (1989) Annu. Rev. Biochem. 58, 453-508

Gorman, C. M., Moffat, L. F. \& Howard, B. H. (1982) Mol. Cell. Biol. 2, 1044-1051

Graham, F. L. \& van der Eb, A. J. (1973) Virology 52, 456-467

Guerini, D. \& Klee, C. B. (1989) Proc. Natl. Acad. Sci. U.S.A. 86, 9183-9187

Ito, A., Hashimoto, T., Hirai, M., Takeda, T., Shuntoh, H., Kuno, T. \& Tanaka, C. (1989) Biochem. Biophys. Res. Commun. 163, 1492-1497

Kincaid, R. L., Giri, P. R., Higuchi, S., Tamura, J., Dixon, S. C., Marietta, C. A., Amorese, D. A. \& Martin, B. M. (1990) J. Biol. Chem. 265, 11312-11319

Klee, C. B., Crouch, T. H. \& Krinks, M. H. (1979) Proc. Natl. Acad. Sci. U.S.A. 76, 6270-6273

Kuno, T., Takeda, T., Hirai, M., Ito, A., Mukai, H. \& Tanaka, C. (1989) Biochem. Biophys. Res. Commun. 165, 1352-1358

Kuno, T., Mukai, H., Ito, A., Chang, C.-D., Kishima, K., Saito, N. \& Tanaka, C. (1992) J. Neurochem. 58, 1643-1651

Liu, J., Farmer, J. D., Jr., Lane, W. S., Friedman, J., Weissman, I. \& Schreiber, S. L. (1991) Cell (Cambridge, Mass.) 66, 807-815

Mitchell, P. J. \& Tjian, R. (1989) Science 245, 371-378

Nielsen, D. A., Chou, J., Mackrell, A. J., Casabadan, M. J. \& Steiner, D. F. (1983) Proc. Natl. Acad. Sci. U.S.A. 80, 5198-5202

Sambrook, J., Fritsch, E. F. \& Maniatis, T. (1989) Molecular Cloning: A Laboratory Manual, Cold Spring Harbor Laboratory, Cold Spring Harbor, New York

Sanger, A. F., Nicklen, S. \& Coulson, A. R. (1977) Proc. Natl. Acad. Sci. U.S.A. 74, 5463-5467

Sauerwald, A., Hoesche, C., Oschwald, R. \& Kiliman, M. W. (1990) J. Biol. Chem. 265, 14932-14937

Takaishi, T., Saito, N., Kuno, T. \& Tanaka, C. (1991) Biochem. Biophys. Res. Commun. 174, 393-398

Vibert, M., Henry, J., Kahn, A. \& Skala, H. (1989) Eur. J. Biochem. 181, 33-39

Wang, J. H. \& Desai, R. (1977) J. Biol. Chem. 252, 4175-4183 